\title{
General Radon Gas Knowledge Test Assessment For BCIT Students
}

\author{
ENVH 8400 Research Method: Journal
}

By: Jamie Zhang 


\title{
General Radon Gas Knowledge Test Assessment For BCIT Students
}

Jamie Zhang ${ }^{1}$, Helen Heacock, $\mathrm{PhD}^{2}$, Jeffrey Ma, $\mathrm{BSc}^{3}$

1. Lead Author, B. Tech Student, School of Health Sciences, British Columbia Institute of Technology

2. Supervisor, School of Health Sciences, British Columbia Institute of Technology

3. Contributor, Fraser Health Authority

\begin{abstract}
Background

Vancouver is located in a generally low-radon hazard zone. However, other parts of British Columbia such as the BC Interior or Northern BC are classified as high-radon hazard zone (or zone 1) due to the geological composition of rocks and soils in those areas. Despite the significant health risks associated with radon gas exposure, many BC residents and people across Canada have little to no knowledge regarding the topic. Since Post-secondary schools, such as the British Columbia Institute of Technology (BCIT), are places where knowledge is distributed and shared to our societies, it is important to assess students' general knowledge background regarding radon gas. The result can then be extrapolated to the general populations.
\end{abstract}

\section{Methods}

An electronic survey was conducted to determine whether students in the six schools at BCIT have different background knowledge level regarding radon gas. The survey also determines students' radon background knowledge based on different geographic regions they reside. The survey was conducted in-person at three main locations across BCIT's Burnaby campus. It was administered using Google Forms and distributed to participants on Microsoft Surface 2.

\section{Results}

The One-way ANOVA statistical analysis result indicated that there is a significant difference in mean radon survey scores among the six various $B C I T$ schools $(p=0.009)$. In addition, the Tukey Test revealed that students from the School of Health Science have an average radon survey score which is significantly different when compared to students from the School of Business. However, it was found that there is no significant difference in the mean radon survey scores between the School of Business and other schools at BCIT. Nonetheless, it was evident that the School of Health Science students had relatively higher radon survey scores and thus, were more knowledgeable regarding radon gas compared to students from the other five schools.

When analyzing survey scores among students residing in various geographic regions, the test showed that there is no significant difference in mean radon survey scores among BCIT students living in various geographic locations $(p=0.46)$.

\section{Conclusion}

Based on the result of the study, the result showed that there is a significant difference in radon gas knowledge among BCIT students who majored in different schools. The School of Health 
Science students were more knowledgeable regarding the topic of radon gas compared to students in other schools. Nonetheless, all BCIT students achieved an average radon survey score of less than five out of ten, which was considered a failure score (Less than five out of ten). This showed that most BCIT students had very limited knowledge regarding radon gas and there were very limited amount of educational initiatives or campaigns available for students at $\mathrm{BCIT}$. BCIT's student association is recommended to create educational sessions across campus to raise student awareness regarding radon gas. At the community level, governments and various agencies such as the BC Lung Association need to work together to create radon awareness campaigns across BC and the rest of Canada. In order to get a more accurate representation of the radon gas knowledge level among people in $\mathrm{BC}$, more research studies need to be conducted in other schools or general population groups.

Keywords: radon, survey, school, BC, knowledge, lung, cancer, risk 


\section{Introduction}

Vancouver is generally known as a region that has very little radon activity. British Columbia's interior has more radon activity due to the geological composition of rocks and soils containing high concentrations of Uranium decay. Since radon activities mostly occur in indoor environments, it is important for people, especially house owners, who live in high-hazard radon areas, to be knowledgeable about radon gas. The objective of this study is to determine whether students in a Canadian post-secondary institution, such as BCIT, have a strong background knowledge regarding radon gas. This project's finding will be important for the local, provincial, federal governments as well as other radon awareness associations to establish educational programs in both schools and the general public. Topics such as basic information of radon, the health effects, guidelines, potential mitigation strategies, general public radon awareness, and public health significance are discussed in detail.

\section{Literature Review}

\section{What is Radon?}

Radon is a colourless and odourless radioactive gas that is released when the radioactive element Uranium breaks down. Uranium is a naturally occurring element that exists in rock, soil, and water. Since it is undetectable by human senses, it can only be identified when quantitative measurement is conducted. The standard unit for measuring radon is picocuries per litre $(\mathrm{pCi} / \mathrm{L})$ or becquerels per cubic meter $\left(\mathrm{Bq} /{ }^{3}\right)$. One $\mathrm{Bq}$ corresponds to one disintegration per second. One $\mathrm{pCi} / \mathrm{L}$ is equivalent to $37 \mathrm{~Bq} / \mathrm{m}^{3}$ (CCOHS 2017). When Uranium gas is released from the ground, it dilutes with the air in the atmosphere and should not pose an immediate risk to humans, animals, or the environment. However, if Uranium gas is released in an enclosed environment such as a house or building (especially if the enclosure does not have adequate airflow movement), the released gas from the ground can accumulate inside the building and pose a significant hazard to human health (Keller, 2001). Radon can enter buildings through soils underground and enter the house through cracks or holes found in the building. It is estimated that $7 \%$ of all Canadians are currently living in homes with radon levels above the current radon guideline of $200 \mathrm{~Bq} / \mathrm{m}^{3}$ (Cheng 2017).

\section{Geographic Locations in British Columbia}

There is a wide distribution of Radon gas present throughout the province of British Columbia. The most radon-prone areas are located to the southeastern and northern quadrants of the province. This is because of their geology consists of an abundance of radioactive elements such as Uranium and Thorium. According to figure 1 , the entire province's area is divided into three zones according to different radon hazards. They are Zone 1, Zone 2, and Zone 3 respectively with Zone 1 being the area with the highest radon hazard.

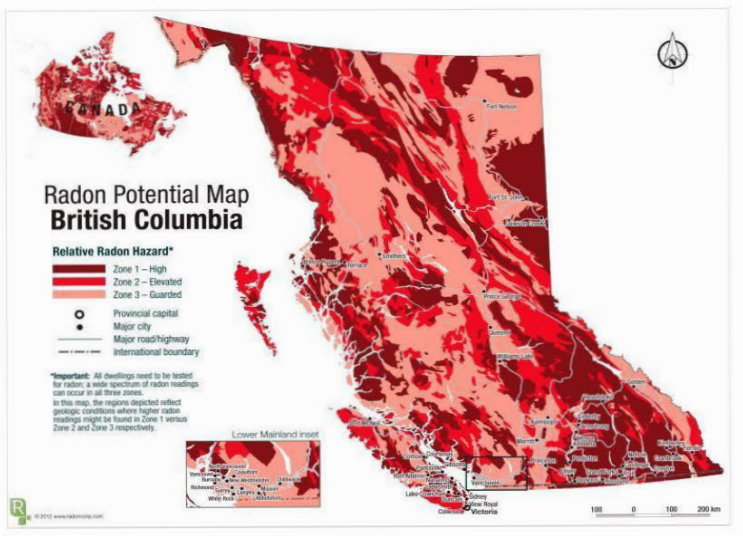

Figure 1. Radon Potential Map for the Province of BC. (Radon Environmental Management Corp. 2017)

According to Statistics Canada, approximately $7 \%$ of homes in Canada have high radon level (Statistics Canada. 2016). Homes which exceed Health Canada's radon concentration limit of 200 
$\mathrm{Bq} / \mathrm{m}^{3}$ are primarily located in the Yukon Territory, Saskatchewan, Manitoba, and Nova Scotia (Statistics Canada. 2016). Since there is such a high presence of radon gas in those areas, it is especially important for municipal and provincial governments in those areas to establish radon awareness programs and campaigns to educate the public. Furthermore, those programs should also encourage various homeowners to request radon testings done for their homes. Other public facilities such as childcare facilities should also be encouraged to be tested.

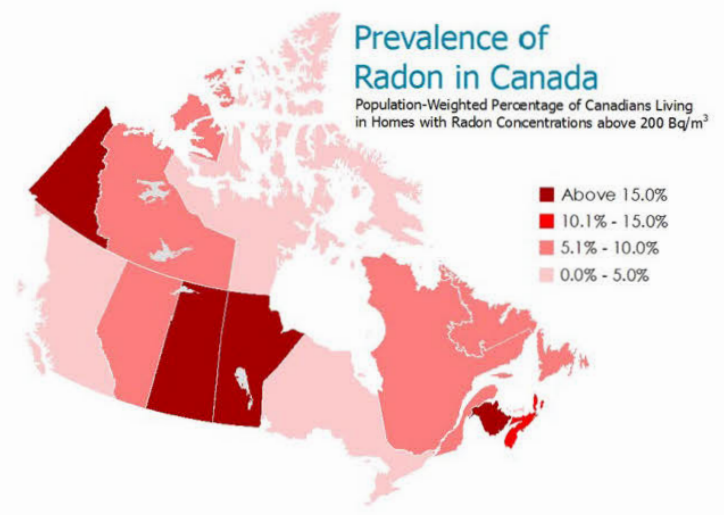

Figure 2. Prevalence of Radon in Canada Population-weighted percentage of Canadians Living in Homes with Radon Concentrations above $200 \mathrm{~Bq} / \mathrm{m}^{3}$. (Statistics Canada, 2016)

\section{Health Effects}

Generally, there are no immediate symptoms associated with short-term exposure to radon gas. However, long-term exposure to radon gas is the leading cause of lung cancer in non-smokers and the second leading cause of cancer development in smokers (WorkSafeBC, 2018). According to statistics, about 16 percent of lung cancer deaths in Canada are a direct result of radon exposure (HeathlinkBC 2017). It is estimated that there is a one in third chance a person will develop lung cancer in one's life time if he or she is exposed to high levels of radon (HeathlinkBC 2017). Smokers are estimated 25 times more at risk from radon exposure than non-smokers (WHO 2017). Because of the risk, the International Agency for Research on Cancer (IARC) classified radon as a human carcinogen in 1988 (Cho, 2013).

The process of developing lung cancer can take many years. As radon decays, it produces "radon daughters" or "radon progeny" which can be inhaled into the lungs through breathing. Once deposited into the lung, those particles can further breakdown and emit "alpha particles". Because those "alpha particles" can release small bursts of energy, they can easily be absorbed by lung tissue and therefore cause lung cell damage. With greater cell damage, there is an elevated risk for cancer development (Health Canada 2017). In order to justify this, a study was done to determine the relationship between the cause of lung cancer and the number of lung cancer attributed to indoor radon exposure in Portugal (Veloso B., 2011). The study also takes other contributing factors such as smoking into account. It used two different models proposed to study the relationship. The result of one model showed that the values are higher which indicate a closer relationship. Depending on the method used, the model also showed that the combination effect of radon and smoking account from 18 to $28 \%$ of lung cancer deaths which are associated with direct indoor radon exposure(Veloso B., 2011). In addition, the study also mentioned that approximately $90 \%$ of deaths attributed to radon occurred among smokers, and $80 \%$ of death is among women (Veloso B., 2011). Although there are a number of limitations to this study, such as the assumption of a uniform indoor radon exposure throughout lifetime, statistical results of the experiment suggested that a much deeper involvement of Portugal's national and regional governments is required in regards to setting stricter mandatory guidelines to prevent or reduce radon exposure by 
individuals working in indoor environments (Veloso B., 2011).

In order to determine if one has been exposed to radon in an indoor environment, Health Canada recommends that the radon levels be tested for a minimum continuous period of three months (Cheng 2017). This form of testing method is highly recommended because radon gas levels constantly fluctuate in a building. In a study published by Cho, he investigated the types of building material with radon emission that exceeded the Canadian Guideline level. Result of the study indicated that cement brick had the highest measured value among all three materials being tested for radon and the study urged government to effectively manage the use of construction materials so that radon emissions are kept to a minimum (Cho, 2013).

\section{General Radon Knowledge Awareness}

\section{Canada}

Throughout Canada, the general public's awareness regarding radon gas is relatively low. According to Statistics Canada, the Household and the Environment Survey found that approximately $45 \%$ of all Canadian household were unaware of radon gas (Statistics Canada 2016). Particularly, residents in Quebec and Newfoundland and Labrador were the least likely to have heard of radon. Among those who had heard about radon, only $59 \%$ were able to correctly identify the term. Households in Nova Scotia, New Brunswick and Quebec were the most likely to have correctly identified it(Statistics Canada 2016). Households in Alberta and British Columbia were most likely have chosen an incorrect answer for radon while describing the term(Statistics Canada 2016). By analyzing those statistics, it is very evident that most Canadian citizens have very limited knowledge of radon.

In 2015, the survey identified approximately $57 \%$ of households that did not live in apartments had heard of radon. Among them, only $6 \%$ had reported have their homes tested for the presence of radon gas(Statistics Canada 2016).

\section{UK}

A population-based radon awareness survey was also conducted in UK and Wale. The survey was designed to evaluate radon awareness and test a locally directed radon roll-out program which was conducted between 2001 and 2005 in England and Wale (Poortinga W., 2011). The goal was to raise radon awareness and test rates across England. During the study, a representative sample of 1,578 residents aged 16 and older who live in radonaffected areas were interviewed(Poortinga W., 2011). The sample population was the "participating" and "nonparticipating" local authorities in "actionable" and "nonactionable" radon-affected areas, and geographic regions with different campaign histories. "Participating" local authorities were ones which decided to enroll in the radon roll-out programs while "Nonparticipating" local authorities were the ones not involved in the roll-out program. "Actionable" areas were areas where residents were most likely test for radon gas presence in an area or building with high radon levels. The study found out that participants living in participating local authorities had higher radon awareness and were more likely to conduct testings at their homes. Similar results were found for participants living in "actionable" areas as compared to those living in "nonactionable" radon-affected areas. Furthermore, radon awareness and testing rates were the highest in Southwest England and lowest in parts of Wale. This implies that the currentin-place radon roll-out-program operated successfully and effectively in raising awareness and test rates across England(Poortinga W., 2011).

\section{Korea}

In 2016, qualitative assessment of the general knowledge level of Korean residents was conducted. In the form of a 
survey, a total of 620 residents were assessed about their general awareness regarding radon gas (Geon-Woo Lee, 2016). The survey revealed that residents of Korean homes had little awareness regarding the source of radon, exposure routes and contamination levels. The excess risk of lung cancer development after exposure for 70 years was determined to be 55 people for every 10,000 people in detached houses located in high radonlevel areas(Geon-Woo Lee, 2016). Compared to the effects of radon exposure in workplaces and schools, the health risks from radon in Korean homes were especially high and it was determined that effective radon education initiatives need to be developed(Geon-Woo Lee, 2016).

\section{Radon Awareness by Schools}

Since different schools at BCIT have courses with their respective content in the curriculum, it will be interesting to discover the general knowledge of BCIT students regarding the topic of radon gas. Some BCIT schools such as the School of Health Science would have more science-oriented courses designed in many of its programs. For example, the Occupational Health and Safety programs have a number of courses such as the "Occupational Hygiene" course where students are taught about various hygiene topics which include "lonizing and Non-ionizing radiations" (BCIT 2018). Information about radon gas would be briefly mentioned in this topic. In Health Science's Radiation Therapy program, there are a number of courses which involve the topic of radiation safety for the public and occupationally exposed personnel (BCIT 2018). The topic for radon gas is also included in those courses. For instance, a course called "Physics for radiation therapy" specifically talk about the physics behind radioactivity (BCIT 2018). In the Nursing program, one particular course which stood out the most is the "Nursing Knowledge 1". According to the course outline, it specifically states that the course will also "incorporates knowledge from sciences and other disciplines as it relates to specific exemplars." (BCIT 2018)

The School of Construction and the Environment has some programs which include courses that may have radon as a topic or as part of a topic. For instance, the Building Construction Technology program has a series of courses called "Materials and Methods"(BCIT 2018). The course introduces students to various construction materials and their physical and chemical make-up (BCIT 2018). Because communities in high radon hazard zones (zone 1 and zone 2 ) have recently updated its BC building code measures in 2013 (The Lung Association 2018), students may be exposed to the topic of radon in this course.

On the other hand, Schools such as Business, Transportation, Energy, and Computing and Academic Studies have courses which are mostly unrelated to radon gas. Students are not as knowledgeable as students from the other two Schools.

\section{Guidelines}

\section{Canada}

There are no known Acts and Regulations governing the maximum exposure limit for radon currently in Canada. The current Canadian Radon Guideline criteria for the maximum exposure is $200 \mathrm{~Bq} / \mathrm{m}^{3}$

(Cheng 2017). If this criterion is exceeded, Health Canada recommends remediation be performed. In this context, remediation refers to all processes used to reduce the amount of radon present in any home or building. When remediation procedures are taking place, the guideline advises that the radon level should be reduced to a value as low as practicable. This means that mitigation methods and radon reduction should be evaluated in a costeffective manner. According to the Health Canada guideline, if the radon level is measured to be between 200 and 600 $\mathrm{Bq} / \mathrm{m}^{3}$, then the mitigation timeframe for taking action should be within the next two years (Cheng 2017). If the measured radon 
level is above $600 \mathrm{~Bq} / \mathrm{m}^{3}$, then it is recommended that the building owner need to correct the problem within a one-year time frame.

Health Canada also collaborates with the Federal Provincial Territorial Radiation Protection Committee (FPTRPC) to review potential health risks associated with radon exposure. This group conducts risk assessments to determine whether current guidelines should be updated to be more broadly applicable and more protective than the previous guideline (Health Canada 2017). Other Canadian Codes also adopted measures to protect from radon exposure. For instance, the 2010 National Building Code requires protection from radon by introducing the "soil gas barriers" (Almeida, 2013). Other examples include Canada Labour Code, Naturally Occurring Radioactive Material Guidelines, and Worksafe BC which all include occupational policies that protect workers from high levels of radon(Almeida, 2013).

\section{Europe}

The issue of radon has been subject to regulatory control in the European Union and in other European countries. This occurred after the International Commission on Radiological Protection (ICRP) made 50 recommendations regarding lung cancer risk from exposure of radon in public workplaces. In order to protect worker's safety against radon exposure in an indoor environment, the ICRP recommends a reference level for indoor exposure in existing buildings of 20 $\mathrm{mSv} / \mathrm{y}$ (corresponding to $400 \mathrm{~Bq} / \mathrm{m}^{3}$ ) and a design level of $200 \mathrm{~Bq} / \mathrm{m}^{3}$ for future construction, implying a protection of new buildings against radon. The ICRP also recommends that protection against radon should be extended to include the general public. This issue was brought up in the BSS Council Directive 2013/59/Euratom, which is a directive aimed at establishing uniform basic safety standards for the protection of the health of individuals subject to occupational exposures, besides the medical and public exposures against the dangers arising from ionising radiation(European Agency for Safety and Health at Work, 2018). After that, a need to develop a regulatory frame focusing on the reduction of radon exposure was suggested(European Radon Association, 2017). As a result, the reference level for the annual average activity concentration in air was lowered to a maximum value of 300 $\mathrm{Bq} / \mathrm{m}^{3}$. However, other EU countries have their own practices and regulations. This creates difficulties in terms of developing a national radon action plan as required by the BSS. As a first step in developing a uniform radon action plan, best practices in mitigating radon levels have been adopted from countries that exhibit outstanding practices in dealing with radon regulation (European Radon Association, 2017).

\section{United States}

Very similar to Canada and Europe, there is no regulation governing the maximum exposure limit for radon exposure because there is no known safe limit for exposure to radon. In the United States, the average indoor radon level is measured to be about $37 \mathrm{~Bq} / \mathrm{m}^{3}$ (EPA, 2013). However, the United States Environmental Protection Agency (EPA) and U.S. Surgeon General recommend that people should fix buildings with radon levels at or above $148 \mathrm{~Bq} / \mathrm{m}^{3}$. They also recommend people fix homes and buildings which have a detected radon measurement between $74 \mathrm{~Bq} / \mathrm{m}^{3}$ and 148 $\mathrm{Bq} / \mathrm{m}^{3}$ (EPA, 2013). The EPA also set their reference level radon guideline to 150 $\mathrm{Bq} / \mathrm{m}^{3}$ (EPA, 2013).

\section{Potential mitigation measures}

\section{Old buildings}

If the radon concentrations have exceeded the maximum exposure levels outlined in the above guidelines, various mitigation measures need to be implemented to reduce the radon levels to below the maximum exposure limit. For old building 
constructions, those mitigation methods include (Cheng 2017):

- Increasing under-floor ventilation

- Installing a radon pump system in the basement

- Improve the overall ventilation of the house/building

- Installing a heat recovery ventilator (HRV) or energy recovery ventilator (ERV)

- Sealing all cracks and holes in the floors and walls

- Create blockages between the basement and the rest of the building as to minimize the spread of radon gas throughout the building

\section{Newer buildings}

The National Building Code of 2010 was adopted by the province of $\mathrm{BC}$ and it divides the province into two zones: zone 1 and zone 2 . Within zone 1 , it is required that a sub-slab depressurization system consisting of a capped radon pipe, label, and $100 \mathrm{~mm}$ of granular material be installed in order to reduce the radon levels (Cheng 2017). This is also a type of Active Soil Depressurization where radon in the soil beneath the foundation of a building is collected and exhausted outside through a vent pipe (Almeida, 2013). This method is proven to be an effective approach because it offers 80 percent or greater radon reductions(Almeida, 2013). With updates to the 2012 BC Building Code, it then requires the extension of the radon pipe to the exterior of the building at the time of the construction. This is considered to be the strongest protective measures against elevated radon levels in a building in Canada. (Cheng 2017) Another method to reduce the radon levels for newly constructed buildings is to use nonpermeable membranes such as plastic sheets which can be placed over the sand or gravel base before the concrete foundation is poured(BCCDC 2017).

\section{Program development}

In an effort to better protect the public; various radon mitigation programs were developed. For instance, the Canadian National Radon Proficiency Program (CNRPP) was developed as a certification program to establish guidelines for training professionals in radon services. The program's core mission is to ensure all Canadians have adequate access to a certified radon professional when it comes to mitigating radon levels (Cheng, 2017). Health Canada also developed the National Radon Program in which it focuses on five major components in order to reduce the public health risks associated with overexposure to radon levels. Those five components are: facilitating radon testing projects, conducting radon research, establishing database and mapping, raising public health awareness through the development of radon education and awareness programs across Canada, and having a national radon level available for testing purposes (Cheng, 2017). Other national radon outreach strategies may include the distribution of radon education materials, designating a "radon action month: November", and events/conferences relating to radon mitigation (Cheng, 2017).

On a provincial level in $\mathrm{BC}$, radon programs can consist of strategies such as coordinating with regional and federal government, establishing public forums relating to radon, raising awareness through community health fairs and tradeshow exhibition booth displace, involving media interviews, and addressing public inquiries on radon (Cheng, 2017).

\section{Public Health Significance}

From the content discussed above, it is clear that excessive exposure to radon can increase an individual's risk of developing lung cancer. This is because ionizing radiation can cause significant tissue damage through the transfer of energy to living cells. This in turn may cause 
molecular changes within a human body through the creation of free radicals (Houwers, 2016). If the exposure is high enough, the repair process may not restore the damage and thus can cause cell death or continued cell proliferation which can lead to various types of cancers such as lung, thyroid, and skin (Health Canada 2017).

The release of radon gas can be classified as a form of ionizing radiation emission in which it is considered to be a serious health concern because of its ability to affect DNA and cause the molecules of the body to become charged and deemed more reactive (CCOHS, 2017). lonizing radiation generally can be found in three primary forms: alpha, beta and gamma. Although Alpha particles cannot penetrate the skin, they may be inhaled and ingested by humans because of their relatively large particle size (Houwers, 2016). Beta particles have fast moving and high energy characteristics, but their ability to damage tissue is very limited due to their small particle size (Houwers, 2016). Gamma radiation is released as the most dangerous form of ionizing radiation because of its ability to travel a great distance (Houwers, 2016).

Other health effects from exposure to radiation can be grouped into two other categories: deterministic or stochastic. In order to meet the definition of deterministic effect, Health Canada established the following definition: "a high radiation threshold of $500 \mathrm{mSV}$ over a short period of time (Hour)". Side effects can include nausea, vomiting, diarrhea, hair loss, immunosuppression, nervous system damage, and even death (Houwers, 2016). Once $500 \mathrm{mSV}$ is reached, the severity of those symptoms will have a direct correlation with the amount of overall radiation being absorbed (Houwers, 2016).

Stochastic effects occur when the threshold is below $500 \mathrm{mSV}$. In this type of health effect, cancer and birth defects are the most obvious health risks. With exposure over $100 \mathrm{mSV}$, there is a strong correlation between the amount of exposure and the degree of risk for developing cancers. Under $100 \mathrm{mSV}$, it seems that the exposure is more related to the number of exposures an individual receives (Houwers, 2016).

This would entail that additional epidemiological studies are required to find out the health risks associated with low level exposure of the radiation.

The threat of radon occurs almost anywhere. Because radon gas has the ability to result in people develop lung cancers without them knowing, it is important that our municipal, regional, and federal government can collaborate in an effort to minimize the risks of radon exposure in an indoor environment. This goal can be achieved by developing programs to ensure a higher level of radon knowledge can be achieved by the general public. In addition, the results of this study helps to raise awareness among government officials, and third party agencies in creating a safer and healthier environment. The overall objective of this project is to create a radon-safe environment for all people across Canada. By knowing the survey results, governments and relevant radon awareness agencies can focus on develop the most cost-effective radon knowledge education initiative across Canada.

\section{Materials and Methods}

\section{Material}

An electronic survey was developed using a platform called "Google Form"(Google 2018). The survey was conducted using a tablet called Microsoft Surface 2. Internet access was provided by BCIT's campus wide WIFI network. The survey was handed to participants one at a time on campus. The survey consisted of three major sections: Survey consent form (See Attachment 2 in Appendix), demographics questionnaires, and radon knowledge test questionnaires. There were a total of fifteen multiple choice questions: six questions 
from the part I Demographics and nine questions from Part II Radon Knowledge Test. All questions were created based on credible sources, such as lecture notes from various Environmental Health courses, and were approved by the course instructor for ENVH 8410, Applied Research Project. The survey questions were also developed based on frequently asked questions about radon on the internet (Radon Technologies Inc. 2007).

\section{Methods}

An electronic survey, called "Google Forms"(Google 2018), was conducted in person on a face-to-face basis at the BCIT Burnaby campus. This survey method was chosen because it is the most effective way to gather immediate survey results and yield honest responses from respondents. In addition, participants would be monitored in which they were not permitted to receive any help during the survey. This would truly reflect their knowledge level toward the survey content.

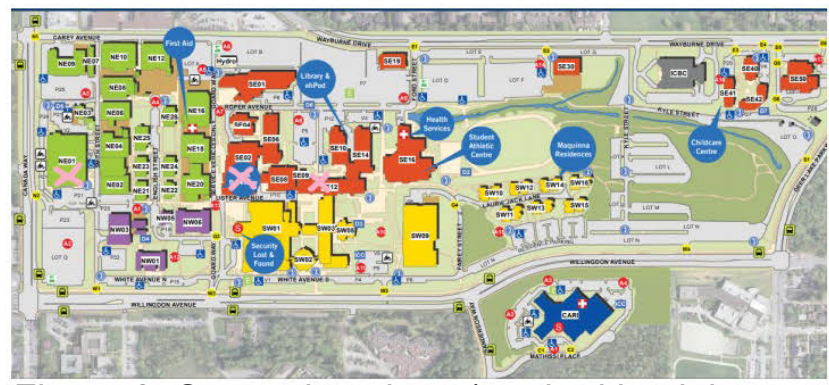

Figure 3. Survey locations (marked in pink crosses) at BCIT's Burnaby campus. (BCIT Facility and Campus Development 2018)

In order to achieve a uniform distribution of results among respondents from various schools, the survey was conducted at three main locations around the campus: Tim Horton's cafeteria, the Great Hall, and NE1 cafeteria(Figure 3). Those locations were chosen because there were usually a large number of students present during their lunch breaks and a continuous flow of students throughout the afternoon hours.
The geographic locations were also uniformly dispersed across the campus. The school days chosen for conducting the surveys were Monday (March 19, 2018), Monday (March 26, 2018), Tuesday (March 27, 2018), and Tuesday (April 3, 2018). Those days were chosen to achieve a more representative survey result in a roughly two-week period. Surveying time frame was between two to six o'clock in the afternoon of a school day (Monday to Friday). The time period was chosen because there were usually a large number of students present in campus cafeteria during their afternoon breaks.

Participants of the surveys were chosen based on the simple random sampling method (Heacock 2017). This meant choosing participants at random encounters in a predetermined sampling location. In this way, everyone had an equal chance of being selected. The method could yield more accurate and uniform data generated.

After each participant completed the survey, a score out of ten was given based on the answers given by the respondent. The answers given were automatically graded by Google Form according to the correct answer for each question. The correct answer was set by the principal investigator based on all credible research material. Finally, the survey score was computed for statistical analysis.

\section{Inclusion and exclusion criteria}

This project was conducted to include all part-time and full-time BCIT students from all six schools: School of Computing and Academic Studies, Health Science, Business, Construction and the Environment, Energy, and Transportation. The populations who were not involved in the study were people who were not BCIT students, such as BCIT instructors, employees, visitors, and general public. Only BCIT students were involved for the 
purpose of this project because they are well represented at BCIT.

\section{Results}

\section{Schools comparison}

Descriptive Data

In this study, the Microsoft Excel (2010) was used to conduct descriptive statistical analysis. This included the determination of descriptive statistics such as means, medians, and standard deviations of the measured data (See Attachment 5 in Appendix). The data type for the project was classified as numerical and a one-way ANOVA test was used to perform comparison among the mean radon survey scores in different schools of BCIT.

Below are the statistical data generated by Microsoft Excel(2010), and NCSS Data Analysis 11.

Table 1. Microsoft Excel Descriptive data Single Factor ANOVA from various BCIT's schools comparison

\begin{tabular}{|l|l|l|l|l|}
\hline Groups & Count & Sum & Average & Variance \\
\hline Business & 52 & 146 & 2.81 & 5.06 \\
\hline $\begin{array}{l}\text { Construction } \\
\text { and the } \\
\text { Environment }\end{array}$ & 33 & 100 & 3.03 & 4.91 \\
\hline $\begin{array}{l}\text { Health Sciences } \\
\text { Other }\end{array}$ & 30 & 93 & 3.10 & 3.96 \\
\hline Othen & 112 & 4.48 & 3.43 \\
\hline
\end{tabular}

Table 2. Microsoft Excel data for the mean, median, and mode radon survey score values for the six schools (four groups) at BCIT.

\begin{tabular}{|l|l|l|l|l|}
\hline & Business & $\begin{array}{l}\text { Construction } \\
\text { and the } \\
\text { Environment }\end{array}$ & $\begin{array}{l}\text { Health } \\
\text { Sciences }\end{array}$ & Other \\
\hline Mean & 2.81 & 3.03 & 4.48 & 3.10 \\
\hline Median & 3 & 3 & 5 & 3 \\
\hline Mode & 0 & 4 & 5 & 2 \\
\hline
\end{tabular}

What BCIT school are you currently enrolled in? 150 responses

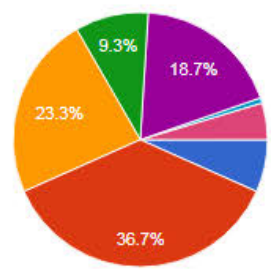

Computing and Academic Studies - Business Construction and the Environmen - Energy - Health Sciences - Transportation Prefer not to answer

Figure 4. Survey responses by Schools (Google Form 2018)

A total of 150 responses were generated throughout the study(Figure 4). The School of Business had the most responses $(36.7 \%)$ while the School of Transportation saw the least number of responses $(0.7 \%)$. Because a minimum of thirty sample size was desired for a normally distributed bell curve, the "Other" group in Microsoft Excel consisted of combined responses from the School of Energy, Transportation, Computing and Academic Studies, and "Prefer not to answer". Furthermore, a total of ten responses were eliminated from the data because those responses were considered not truly reflective of the participants' true background knowledge of radon gas. Based on the Microsoft Excel descriptive data, it was clear that the mean radon survey score for the School of Health Science was relatively higher than the other three groups' scores. 
Insights

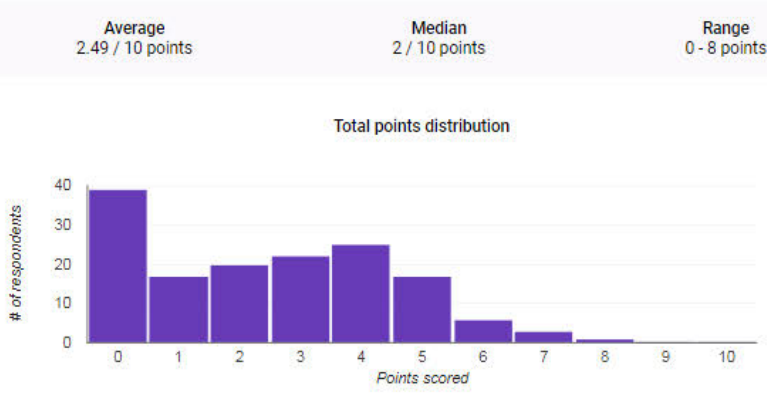

Figure 5. Total survey score distribution (Google Forms 2018)

Nonetheless, all of the schools at BCIT achieved a mean score value that was no more than the passing score for the survey(Figure 5). However, there were also large variances observed for each school's score respectively. The large variance meant that the mean score values of the survey did not represent the overall knowledge level in each school. More surveys need to be conducted to minimize variance.

A potential outlier would come from students who already took courses about radon. Other instances occur when the respondents may chose to "rush" through the survey because they were in a hurry or were being distracted at the moment. Finally, there might be a slight chance where responses were duplicated. These results would all cause a skew of the normal distribution curve at either the high or low score end of the spectrum. In this study, because there weren't many outliers, and most people who took radon-related courses could truly reflect their knowledge level at the time of the survey, it was decided that those results were kept for statistical analysis. For people who may potentially "rush" through the survey, careful decision was made to select only those that were not busy. In addition, the length of the survey was explained to the participants beforehand and asked if they have the time to do those surveys. In order to minimize duplication, the survey was conducted at different time frames at different days.
There was one instance where the participant did not complete the survey. As a result, the survey result for that respondent was excluded.

\section{Inferential Data}

In order to conduct inferential statistics, the NCSS Data Analysis software (NCSS Statistical Software 2018) package was used. The means of radon survey scores measured among the different schools of BCIT were compared among themselves to see if they were significantly different from each other. The hypothesis for the one-way ANOVA is listed as follows:

Ho: There is no significant difference among the mean radon survey scores of BCIT's Schools of Health Science, Construction and Environment, Businesses, and other schools.

Ha: There is a significant difference among the mean radon survey scores of BCIT's Schools of Health Science, Construction and Environment, Businesses, and other schools.

Table 3. NCSS Data Analysis 11 Oneway ANOVA Inferential Statistical data from various BCIT's schools comparison

\begin{tabular}{|c|c|c|}
\hline & Result & \multicolumn{1}{|c|}{ Conclusion } \\
\hline $\begin{array}{c}\text { Probability } \\
\text { Level (p- } \\
\text { value) }\end{array}$ & 0.009 & $\begin{array}{l}\text { There is a significant difference } \\
\text { among the mean radon survey } \\
\text { scores of BCIT's Schools of } \\
\text { Health Science, Construction } \\
\text { and Environment, Businesses, } \\
\text { and other schools. }\end{array}$ \\
\hline $\begin{array}{c}\text { Reject Ho at } \\
\mathbf{0 . 0 5}\end{array}$ & Yes & \\
\hline $\begin{array}{c}\text { Power: (Alpha } \\
=\mathbf{0 . 0 5 )}\end{array}$ & 0.80 & \\
\hline
\end{tabular}

Based on the above inferential statistics, the p-value for the Kruskal-Wallis One-Way ANOVA was 0.009 which was less than 0.05 . Therefore, the null hypothesis was rejected and it was concluded that there 
was a significant difference among the mean radon survey scores of BCIT's Schools of Health Science, Construction and Environment, Businesses, and other schools. Furthermore, the results of the Tukey-Kramer Multiple-Comparison Test and the Scheffe Post hoc test were two tests capable of detecting groups which were significantly different from one another. The Tukey-Kramer MultipleComparison Test indicated that the "School of Health Science" group's mean was significantly different from the mean value from "School of Business". This test was the most acceptable general method for all pairwise comparison as the $p$-values for the test were exact with balanced design (StatsDirect Ltd., 2018). On the other hand, the Scheffe Post hoc test did not indicate a difference among the groups because it gave a very conservative weighting against the risk of having type I error. Therefore, it was less powerful for the detection of true differences among groups(StatsDirect Ltd., 2018).

\section{Sources of errors}

The potential for beta error was 0.20 in this study. It was calculated by subtracting power $(0.80)$ from 1 . The existence in beta errors was due to inadequate data points collected during the survey. In order to lower beta error, more surveying need to be performed.

\section{Regional comparison}

\section{Descriptive Data}

A two sample T-test was conducted to compare the mean radon survey scores between BCIT students living in the Lower Mainland and other regions.
Which area of $\mathrm{BC}$ are you from? 150 responses

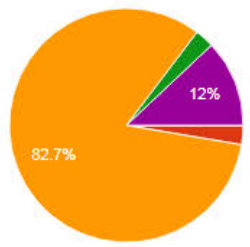

Northern (e.g. Smithers, Terrace, Prince George)

- Interior (e.g. Kelowna, Kamloops (venon)

- Lower mainland (e.g. Vancouver, Burnaby, Richmond, Tri-Cities, Delt Surrey) - Vancouver Island - Other - Prefer not to answer

Figure 6. Survey responses by region (Google Forms 2018)

Within the 150 responses, the majority $(82 \%)$ were from the Lower mainland while the remaining $(18 \%)$ were from outside the region (Figure 6).

Table 4. Microsoft Excel Descriptive data Two Sample T-test for BCIT students living in the Lower Mainland and other regions

\begin{tabular}{lrr}
\hline & Lower mainland & Other \\
\hline Mean & 3.198276 & 3.291667 \\
Variance & 4.821214 & 4.824275 \\
Observations & 116 & 24 \\
Hypothesized Mean & & \\
Difference & 0 & \\
df & 33 & \\
t Stat & -0.18962 & \\
P(T<=t) one-tail & 0.425385 & \\
t Critical one-tail & 1.69236 & \\
$\mathrm{P}(\mathrm{T}<=\mathrm{t})$ two-tail & 0.850769 & \\
t Critical two-tail & 2.034515 & \\
\hline
\end{tabular}

Accord to the above result, it was very clear that the mean radon survey scores between the two groups ("Lower mainland" and "Other") were below the passing grade of five out of ten. However, the mean survey score from the "Other" groups was slightly higher than the "Lower mainland" group. This indicated that students residing in regions outside of lower mainland had a slightly higher background knowledge regarding radon gas. Those students might be slightly exposed to the topic via TV or 
social media mentioning about radon gasrelated contents.

\section{Inferential Data}

The means of radon survey scores measured among BCIT students living in the Lower Mainland and areas outside of Lower Mainland were compared to see if they are significantly different from each other.

The hypothesis for the Two sample T-test is listed as follows:

Ho: The mean radon survey score from $B C I T$ students who reside in Lower Mainland is more than or equal to the mean radon survey score from BCIT students who reside outside of Lower Mainland

Ha: The mean radon survey score from $B C I T$ students who reside in Lower Mainland is less than the mean radon survey score from BCIT students who reside outside of Lower Mainland

Table 5. NCSS Data Analysis 11 Inferential Statistical data Two Sample Ttest for BCIT students residing in and outside Lower Mainland

\begin{tabular}{|c|c|c|}
\hline & Result & Conclusion \\
\hline $\begin{array}{c}\text { Probabilit } \\
\text { y Level ( } p- \\
\text { value) }\end{array}$ & 0.46 & \multirow{3}{*}{$\begin{array}{l}\text { The mean radon survey } \\
\text { score from BCIT students } \\
\text { who reside in Lower } \\
\text { Mainland is more than or } \\
\text { equal to the mean radon } \\
\text { survey score from BCIT } \\
\text { students who reside } \\
\text { outside of Lower Mainland }\end{array}$} \\
\hline $\begin{array}{l}\text { Reject Ho } \\
\text { at } 0.05\end{array}$ & No & \\
\hline $\begin{array}{c}\text { Power: } \\
\text { (Alpha = } \\
0.05)\end{array}$ & 0.073 & \\
\hline
\end{tabular}

From the Mann Whitney $U$ test or the Wilcoxon Rank-Sum Test(Heacock, 2017), it showed that the $p$-value was 0.46 . This value was much greater than the 0.05 cutoff value. Therefore, it could be concluded that the mean radon survey score from $\mathrm{BCIT}$ students who reside in Lower Mainland was more than or equal to the mean radon survey score from BCIT students who reside outside of Lower Mainland. Although students residing in areas outside of the Lower Mainland may be slightly knowledgeable about radon gas compared to Lower Mainland students, the mean radon survey scores from students outside of Lower Mainland did not show a statistically significantly higher mean score than the "Lower Mainland" group.

Therefore, the difference in geographic locations may not be an influential factor for the result of the survey scores.

\section{Sources of errors}

For analysis by regions, the potential for beta error was 0.927 in this study. This value was calculated by subtracting the power (0.073) from 1. The existence in beta errors was due to inadequate data points collected during the survey. In order to lower beta error, more surveying need to be performed. In fact, the "Other" group only got twenty-four responses. This number was not adequate in generating a powerful statistical analysis. Hence the power was only 0.073 .

\section{Discussion}

\section{Schools comparison}

The result of the one-way ANOVA test showed that there was a significant difference in radon knowledge among students studying in different BCIT schools. For the purpose of this study, the categories were: (i)Health Science, (ii)Business, (iii)Construction and the Environment, and (iv)Other (representing results from School of Energy, Transportation and Computing and Academic Studies). Comparing mean knowledge scores between the four schools, the Kruskal-Wallis One-Way ANOVA test resulted in a p-value of 0.009 . 
Furthermore, the Tukey-Kramer MultipleComparison Test result showed that only the School of Health Science was significantly different from the School of Business. According to the test, the mean radon survey score for the School of Health Science was averaged 4.48 out of 10 . The mean radon survey score for the School of Business was averaged 2.81 out of 10. This large difference in scores reflected the general background knowledge of students from the two different schools at the time of the survey. This result showed that students from the School of Health Science may had taken courses which have contents about radon. Conversely, the School of Business does not offer many science-oriented courses. Hence, students' radon knowledge in the School of Health Science was relatively higher than other schools.

Although the mean radon score for the School of Health Science was relatively higher compared to other schools, it was below the passing grade, which was set at five out of ten. This result showed that many of the students at BCIT did not have a good understanding about the topic. The suspected reason could come from the fact that Vancouver and people living in the lower mainland were in a low-hazard zone according to the Radon Potential Map in BC. As such, there may not have been opportunities for students to be exposed to radon material throughout their studies.

\section{Regional comparison}

Because Vancouver is a low risk area for radon gas, and $\mathrm{BCIT}$ students come from all over the province, the question of whether students whose main location of residence is in a high radon area arose. In order to determine this, a Two-Sample Independent T-test statistical analysis test was conducted. The $p$-value for the MannWhitney U/ Wilcoxon Rank-Sum test was 0.46 , read off at the "Alternative hypothesis Diff > 0" line (Heacock 2017). According to this $p$-value, it was concluded that the null hypothesis was not rejected and therefore concluded that the mean radon survey scores achieved by students living in the lower mainland of BC was more than or equal to the survey scores achieved by students living outside the Lower mainland. This implies that there was an overall lack of awareness among BCIT students despite the geographical locations they were from. However, according to descriptive data, the mean survey score from lower mainland students (3.20) was slightly lower than the survey scores from students residing elsewhere(3.29). This result was expected because lower mainland is generally a low-hazard region for radon compared to other parts. Students residing outside of lower mainland had stronger awareness because those places may have relatively improved radon awareness programs in place to educate the public.

According to the Households and the Environment Survey conducted by Statistics Canada in 2015, only 55\% of all Canadian households indicated that they had heard of radon (Statistics Canada 2016). Among those who heard about radon, only $59 \%$ were able to correctly identify what it was when presented with a list of possible descriptions (Statistics Canada 2016). Finally, British Columbia was most likely to have chosen an incorrect description for radon when asked in the survey. The result of the general knowledge test survey conducted at BCIT reflected about the general public's knowledge regarding radon in BC. This is because schools such as a post-secondary institution serve as a place where knowledge originates and will be shared with our communities. With low survey scores from BCIT, it can be implied that the knowledge level of the general public in BC toward radon was also low. In addition, since radon was not very common in the lower mainland, it may be "normal" for people to not have a good awareness toward radon. 
In other parts of the world, radon general knowledge surveys were also conducted in South Korea to assess the public's general knowledge regarding the topic in 2016. The survey revealed that residents of Korean homes had little awareness regarding the source of radon, exposure routes and contamination levels. In fact, the excess risk of lung cancer development after exposure for 70 years was determined to be 55 people for every 10,000 people in detached houses located in high radon-level areas(Geon-Woo Lee, 2016). This astonishing number just showed the lack of awareness among Korean home owners and a lack of effort in establishing effective radon education initiatives by the South Korean government. Based on previous radon survey studies, it could be generalized that the topic of "radon gas" is unfamiliar to people worldwide and effective educational campaigns need to be implemented.

The overall results of the study were considered valid because all the technical questions were created according to credible sources such as BCIT's course material and online resources from an accredited organization such as the BC Lung Cancer Association. Furthermore, all of these questions were approved by study coordinator, Helen Heacock. During the survey, the students were not allowed to receive any help either from the internet or another person. This reflected the true background knowledge of the students surveyed. However, there would still be a number of methodological limitations.

\section{Limitations}

There were some limitations involved during the surveying process. One major difficulty encountered was the uneven distribution of survey results based on various schools at $\mathrm{BCIT}$. The researcher was aiming to obtain at least 30 surveys completed per school. Since students from various schools can only be assumed to be mostly concentrated at certain locations across the campus, the exact number of survey outcomes per school cannot be controlled. Because of a low response rate from the following BCIT schools; Computing and Academic Studies, Energy, and Transportation, it was necessary to lump them together under the category "Other". In this way, a more robust statistical analysis can be conducted. The same concept was used for analyzing and comparing $\mathrm{BCIT}$ students coming from different regions. In this example, the number of survey respondents who did not click on the "Lower mainland" option was combined together into a group named "Other".

Another challenge arose when describing the survey to respondents. Initially, the approximate length of the survey was not disclosed to the respondents. There were several instances the respondents inquired about the length of the survey before participating. Other times respondents rejected the survey invitation when the length was not told. In this situation, the method of delivering the message prior to the survey was changed by including the approximate length of survey during the introduction. This strategy increased the likelihood and frequency of survey participation among students and therefore lowered the overall survey time.

Some respondents may have had difficulty understanding the English language. One method to resolve this problem was by explaining certain words in the survey in a way that did not directly disclose the correct answers to the questions. The strategy increased the survey response validity as it lowered the chances of respondents answering the survey questions without understanding the meaning and nature of those questions.

Although survey respondents were verbally explained about highlights from the survey's consent form, many of them did not fully read and understood the content of the consent form before proceeding to 
complete the survey. These results would not truly reflect the respondents' background knowledge. Evidence of this occurring could be seen when the time gap between surveys completed was no more than two minutes. Those surveys usually contain a lot of "Do not know" answers. Those instances may imply that the respondents did not answer the survey questions seriously or they did not understand many of those questions before answering them. This issue can be improved by strongly emphasizing the importance of reading the consent form before proceeding to the survey. Another way of resolving this was to exclude those survey results from statistical analysis as they were not a true reflection of the respondents' background knowledge. This increased the validity of the survey by removing outliers from the data. For this project, a total of ten responses were excluded from the original data set.

Finally, there might be a possibility of acquiring duplicate results. It occurred when the same respondent was surveyed twice due to the lack of facial recognition. In order to minimize this type of error, the survey was conducted at different time frames apart at different school days. Another potential solution to solve this problem is to have the respondent log into their registered e-mails for accessing the survey. However, this may increase the time of the survey and reduce the overall willingness for respondents to participate.

\section{Knowledge Translation and Recommendations}

Post-secondary institutions such as BCIT are centers for knowledge distribution. The findings of this project may greatly reflect the current radon knowledge level for the general public in $\mathrm{BC}$; or more likely, it may represent the radon knowledge of postsecondary students in $\mathrm{BC}$; that is an overall low level of knowledge on radon gas as indicated by knowledge score of less than
$50 \%$ by all respondents. Meanwhile, the results of the survey can greatly contribute to the scientific communities. Although Metro Vancouver and the Lower Mainland are classified as a low-hazard zones for radon concentration (Radon Environmental Management Corp. 2017), many other parts of BC may observe much higher pockets of radon-gas enriched soil(Cheng 2017).

Based on the results of the survey, the federal, provincial, local government, and other various agencies such as the $\mathrm{BC}$ Lung Association may work together to create public radon awareness programs throughout communities across BC to increase public awareness. In addition, campaigns and programs can further encourage residents living in radon-prone areas to get their homes tested. In a postsecondary environment, the school may also consider holding radon awareness programs/campaigns at the campus during lunch hours in an effort raise awareness among students. This is especially important in raising awareness among all $\mathrm{BCIT}$ students since the average radon survey scores across all six schools were below the passing level of $50 \%$. The sharing of knowledge among students can also spread to our communities much efficiently.

Results of the Tukey-Kramer MultipleComparison Test showed that the "School of Health Science" group's mean survey score was significantly different from the mean value from the "School of Business". In fact, the "School of Business" had the lowest average survey score among all four groups compared. This result likely occurred because there were no science-oriented courses mentioning the topic of radon in the School of Business. On the other hand, the School of Health Science has many science-oriented courses in which provide information on radon. A recommendation to boost student's knowledge level is to suggest BCIT's Students Association to establish a "radon information" session during lunch or break particularly for the Business students at BCIT. The speech 
session would not take more than fifteen minutes and it should highlight some of the most important factual and practical information regarding radon gas, such as what is radon gas, what are the associated health risks, where it is primarily found, and how to prevent it from causing harm to human.

Since there were no significant difference found between mean radon survey scores completed by students living in the lower mainland and elsewhere, the provincial and federal governments should consider providing more funding to establish radon awareness programs particularly in highhazard areas. People living outside of Metro Vancouver and the lower mainland were in greater danger as their knowledge level about radon was no different from Vancouverites and lower mainlanders. Partnership among different regulatory bodies and agencies could strengthen the effort to increase awareness across BC and the rest of Canada. Finally, the use of various forms of media such as Facebook, Twitter, TV, and radio can help spread the information in a quick and effective way.

\section{Future Research}

Based on this research project, future student projects can be established to further investigate people's general knowledge level regarding the topic of radon in BC. Those projects may include but are not limited to:

- Assessing the general radon knowledge of BCIT students in the future to compare with the findings from this project. A difference may imply that the newly implemented awareness programs (if any) are effective.

- Assessing the general radon knowledge of students in other BC universities such as UBC, SFU, UFV, Langara, etc. to see how their radon knowledge levels are compared to BCIT.

- Assessing the radon knowledge of all $B C$ residents to see if the results are different from BCIT students' knowledge.

- Conduct various radon testing in buildings/areas suspected of high levels of radon

\section{Conclusions}

Although radon gas poses danger to human health, many people are still either unaware of this term or do not fully understand its health consequences. This project demonstrated that the majority of BCIT students showed little to no background knowledge regarding radon gas. This is very concerning because it may also reflect the degree of awareness among the general public about radon gas. The lack of awareness implies that there are not many awareness campaigns currently available for students and our communities due to various reasons. It is important for postsecondary institutions, such as BCIT, to consider holding radon awareness programs/campaigns at the campus during lunch hours in an effort to raise awareness among students. The sharing of knowledge among students can also spread to our communities much efficiently.

It is also important for local, provincial, federal governments, and other third-party organizations to establish such programs in order to raise people's awareness across $\mathrm{BC}$ and the rest of Canada.

\section{Acknowledgements}

The researcher would like to acknowledge and thank Dr. Helen Heacock for the suggestion of this research topic along with her assistance and support throughout the completion of this project. The researcher would also like to thank Jeffrey Ma, BSc, Environmental Health Tobacco Control 
Officer at the Fraser Health Authority for providing assistance throughout the research project.

\section{Competing Interest}

The author declare that they have no competing interests.

\section{References}

Almeida T.A.(2013), The effectiveness of radon remediation, Retrieved from the $\mathrm{BCIT}$

Repository.

BC Lung Association (2018), Radon Aware

Radon Resources, Retrieved from

http://www.radonaware.ca/radon-

resources/overview.php

BCIT Facility and Campus Development (2018),

Burnaby Campus Map, Retrieved from

https://www.bcit.ca/files/maps/pdf/bcit wayfi

nding.pdf
BCIT (2018), OCHS 4320 - Occupational Hygiene Course Outline, Retrieved from

https://www.bcit.ca/study/outlines/201820507 $\underline{47}$

BCIT (2018), RADT 5103 - Physics for Radiation Therapy 1 Course Outline, Retrieved from https://www.bcit.ca/study/outlines/201730335 $\underline{11}$

BCIT (2018), BSNC 1000 - Nursing Knowledge 1 Course Outline, Retrieved from https://www.bcit.ca/study/outlines/201820651 $\underline{32}$

BCIT (2018), BLDC 1050 - Materials and Methods 1 Course Outline, Retrieved from https://www.bcit.ca/study/outlines/201820556 $\underline{20}$

BC Centre for Disease Control (2017), Radon, Retrieved from

http://www.bccdc.ca/healthinfo/health-yourenvironment/contaminants/radon

Canadian Center for Occupational Health and Safety (2017), Retrieved from https://www.ccohs.ca/

Cheng W. (2017), Radon: An Overview, Retrieved from

https://www.canada.ca/en/healthcanada.html

EPA(2017), Publications about Radon, Retrieved from https://www.epa.gov/radon/publicationsabout-radon

European Radon Association (2017), Radon Regulation, Retrieved from http://radoneurope.org/index.php/activitiesand-events-2/working-groups/radonregulation/

European Agency for Safety and Health at Work (2018), Directive 2013/59/Euratom - protection against ionising radiation, Retrieved from https://osha.europa.eu/en/legislation/directive 
s/directive-2013-59-euratom-protection-

against-ionising-radiation

Google Forms (2018), Radon Knowledge Test Summary, Retrieved from https://docs.google.com/forms/d/1c63pR8UG TdQJlhr40fdn8nftOhOlwZZDpdZ-krwKJ4/edit\#responses

Heacock H. (2017), Module 4. Research Methods Research Design and Data Collection, Retrieved from ENVH 8400 lecture notes.

Heacock H. (2017), Module 5. Research Methods Introduction to Descriptive Statistics, Retrieved from ENVH 8400 lecture notes.

Heacock H. (2017), Module 6. Research Methods Introduction to Inferential Statistics, Retrieved from ENVH 8400 lecture notes.

Heacock H. (2017), Module 7A. Research Methods T-tests, Retrieved from ENVH 8400 lecture notes.

Heacock H. (2017), Module 7B. Research Methods Other Statistical Tests with Numeric Data, Retrieved from ENVH 8400 lecture notes.

Lee G.W., Yang J.Y., Kim K.J.(2016), Estimation of health risk and effective dose based on measured radon levels in Korean homes and a qualitative assessment for residents' radon awareness, Retrieved from $\mathrm{http}: / / 0-$ journals.sagepub.com.innopac.lib. $\overline{b c i t . c a / d o i / f u}$ II/10.1177/1420326X16664387

Health Link BC (2017), Radon in Homes and Other Dwellings, Retrieved from https://www.healthlinkbc.ca/healthlinkbcfiles/radon on October 15, 2017

Health Canada (2017), Government of Canada Radon Guideline, Retrieved from https://www.canada.ca/en/healthcanada/services/environmentalworkplacehealth/radiation/radon/governmentcanada-radon-guideline.html

Houwers K. (2016), Potential Environmental Impact of the Fukushima Daiichi Nuclear Plant Accident: 4 Years Later, Retrieved from BCIT Repository 2017.

NCBI (2017), WHO Handbook on Indoor Radon: A Public Health Perspective., Retrieved from https://www.ncbi.nlm.nih.gov/books/NB K143222/

NCSS Statistical Software (2018), NCSS Data Analysis 11, Retrieved from https://www.ncss.com/software/ncss/

Poortinga W, Bronstering K, Lannon S (2011), Awareness and Perceptions of the Risks of Exposure to Indoor Radon: A Population-Based Approach to Evaluate a Radon Awareness and Testing Campaign in England and Wales, Risk Analysis, Vol. 31, No. 11, 2011

Radon Environmental Management Corp. (2017), Mapping the geologic radon potential in Canada, Retrieved from

Http://www.radonaware.ca/database/files/libr ary/British_Columbia_Radon_Potential_Map.p df

Radon Technologies Inc.(2007), Frequently Asked Questions, Retrieved from http://www.radontechnologies.com/faq.cfm

Staistics Canada (2016), Environment Fact Sheets Radon awareness in Canada, Retrieved from http://www.statcan.gc.ca/pub/16-508x/16-508-x2016002-eng.htm

StatsDirect Ltd. (2018), Multiple comparisons in Analysis of Variance, Retrieved from 
https://www.statsdirect.com/help/analysis of variance/multiple comparisons.htm

The Lung Association (2018), New B.C. Building Code Measures, Retrieved from http://www.radonaware.ca/communityprojects/new-building-code-measures

Veloso B., Nogueira J.R., Cardoso M.F., Lung cancer and indoor radon exposure in the north of Portugal - An ecological study, Retrieved from

https://www.ncbi.nlm.nih.gov/pubmed/220755

$\underline{35}$

WorkSafeBC (2017), Radon, Retrieved from https://www.worksafebc.com/en/healthsafety/ hazards-exposures/radon

World Health Organization (2017), Radon and health, retrieved from http://www.who.int/mediacentre/factsheets/f s291/en/ 